\title{
BMJ Open Prevalence of atopic dermatitis, asthma and rhinitis from infancy through adulthood in rural Bangladesh: a population-based, cross-sectional survey
}

\author{
Courtney J Pedersen, ${ }^{1}$ Mohammad J Uddin, ${ }^{2}$ Samir K Saha, ${ }^{2}$ \\ Gary L Darmstadt (i) ${ }^{1}$
}

To cite: Pedersen CJ, Uddin MJ, Saha SK, et al. Prevalence of atopic dermatitis, asthma and rhinitis from infancy through adulthood in rural Bangladesh: a population-based, crosssectional survey. BMJ Open 2020;10:e042380. doi:10.1136/ bmjopen-2020-042380

- Prepublication history for this paper is available online. To view these files, please visit the journal online (http://dx.doi. org/10.1136/bmjopen-2020042380).

Received 08 July 2020 Revised 23 September 2020 Accepted 29 September 2020

Check for updates

(C) Author(s) (or their employer(s)) 2020. Re-use permitted under CC BY-NC. No commercial re-use. See rights and permissions. Published by BMJ.

${ }^{1}$ Department of Pediatrics, Stanford University School of Medicine, Stanford, CA, USA

${ }^{2}$ Child Health Research

Foundation, Dhaka, Bangladesh

Correspondence to

Dr Gary L Darmstadt;

gdarmsta@stanford.edu

\section{ABSTRACT}

Objective Describe the pattern of atopic disease

prevalence from infancy to adulthood.

Design Cross-sectional household survey.

Setting Community-based demographic surveillance site, Mirzapur, Bangladesh.

Participants 7275 individuals in randomly selected clusters within 156 villages.

Primary and secondary outcome measures The 12-month prevalence of atopic dermatitis (by UK Working Party Criteria (UK criteria) and International Study of Asthma and Allergies in Childhood (ISAAC)), asthma and rhinitis (by ISAAC); disease severity (by ISAAC); history of ever receiving a medical diagnosis.

Results Children aged 2 years had the highest prevalence of atopic dermatitis- $18.8 \%(95 \% \mathrm{Cl} 15.2 \%$ to $22.4 \%)$ by UK criteria and $14.9 \%(95 \% \mathrm{Cl} 11.6 \%$ to $18.1 \%)$ by ISAACand asthma $(20.1 \%, 95 \% \mathrm{Cl} 16.4 \%$ to $23.8 \%)$. Prevalence of rhinitis was highest among $25-29$ year olds $(6.0 \%$, $(95 \%$ Cl\% 4.5 to $7.4 \%$ ). History of a medical diagnosis was lowest for atopic dermatitis (4.0\%) and highest for rhinitis (27.3\%) and was significantly associated with severe disease compared with those without severe disease for all three conditions (atopic dermatitis: $30.0 \%$ vs $11.7 \%$, $\mathrm{p}=0.015$; asthma; $85.0 \%$ vs $60.4 \%, \mathrm{p}<0.001$; rhinitis: $34.2 \%$ vs $7.3 \%, \mathrm{p}<0.001)$ and having a higher asset-based wealth score for asthma ( $29.7 \%$ (highest quintile) vs $7.5 \%$ (lowest quintile), $\mathrm{p}<0.001$ ) and rhinitis ( $39.8 \%$ vs $12.5 \%, p=0.003)$. Prevalence of having $\geq 1$ condition was highest (36.2\%) at 2 years and decreased with age. Having atopic dermatitis (ISAAC) was associated with significantly increased odds ratios (OR) for comorbid asthma (OR 5.56 (95\% Cl 4.26 to 7.26$)$ ] and rhinitis (3.68 (95\% Cl 2.73 to 4.96$))$. Asthma and rhinitis were also strongly associated with each other (OR 8.39 (95\% $\mathrm{Cl} 6.48$ to 10.86)). Conclusions Atopic disease burden was high in this rural Bangladeshi population. Having one atopic condition was significantly associated with the presence of another. Low incidence of ever obtaining a medical diagnosis highlights an important opportunity to increase availability of affordable diagnosis and treatment options for all age groups.

\section{INTRODUCTION}

Atopic diseases are a set of conditions including atopic dermatitis, asthma and
Strengths and limitations of this study

- Despite increasing prevalence of atopic disease in low-income and middle-income countries, there are limited data describing the pattern of atopic disease prevalence across the life course; to our knowledge, this is the first description of the cross-sectional period prevalence of atopic conditions from infancy through adulthood reported from the Indian subcontinent.

- We conducted population-based household surveillance in rural Bangladesh using validated instruments for detection of atopic diseases.

- We lacked longitudinal data that would allow us to suggest a driving mechanism for comorbidity among atopic conditions, such as the atopic march; a prospective cohort study would more easily enable conclusions to be drawn about risk factors and the relationships among the three atopic diseases.

- We were able to identify subjects whose atopic condition was diagnosed by a medical provider, but lacked data on medical management of atopic conditions.

allergic rhinitis that are estimated to affect approximately20 of the world's population. ${ }^{1}$ Atopic dermatitis is the leading contributor to the global burden of skin disease, affecting an estimated 230 million people, while asthma is estimated to affect nearly 340 million people and is the most common chronic disease among children. ${ }^{2}{ }^{3}$ The International Study of Asthma and Allergies (ISAAC) was a global epidemiological effort to standardise research on the prevalence of these conditions. Their data revealed an increasing prevalence of atopic dermatitis, asthma and rhinitis globally, however, with great variations within and between countries. ${ }^{4-6}$ The most rapid increases in prevalence were seen among countries with previously documented low prevalence of 
these conditions and were mostly low-income and middleincome countries (LMICs). ${ }^{57}$

The natural history of atopic conditions classically begins with atopic dermatitis and progresses in an additive manner to include asthma and allergic rhinitis-a pattern known as the 'atopic march. ${ }^{8}$ However, limited research in LMICs suggests that atopic sensitisation is not as strongly correlated with the sequential development of atopic dermatitis, asthma and rhinitis as it is in high-income countries (HICs) where the atopic march was first described. ${ }^{9-11}$ Additionally, despite associations between allergic sensitisation and atopic conditions, the atopic march was not observed among a birth cohort in Uganda. ${ }^{12}$ The authors concluded that environmental exposures in late childhood may dissociate atopic conditions from each other.

The hygiene hypothesis is a widely accepted explanation for both the higher prevalence of atopic diseases in HICs and the trend of increasing prevalence in LMICs as they industrialise, arguing that reduced exposure to microbes early in life increases the risk of developing immunoregulatory disorders including atopic disease. ${ }^{13}$ However, research is beginning to show that these conditions are multifactorial and even within risk factors there can be great variation. ${ }^{1415}$ For example, until recently, helminths have been thought to be universally protective against the development of atopic conditions but recent evidence shows that these associations are heterogeneous and vary drastically even within helminth species. ${ }^{16} 17$

While much of the global effort to understand atopic conditions has focused on the paediatric population, it is essential to understand the prevalence of atopic conditions in children and adults in order to inform policy and the implementation of interventions that target the appropriate populations. This is especially true as the prevalence of these conditions increases in LMICs. Here, we present the findings of a cross-sectional study of the period prevalence of atopic conditions from infancy to adulthood in rural Bangladesh.

\section{METHODS}

The methods and reporting of this study followed Strengthening the Reporting of Observational Studies in Epidemiology guidelines (https://www.strobe-statement. org/fileadmin/Strobe/uploads/checklists/STROBE_ checklist_v4_combined.pdf).

\section{Study population}

The study took place within the demographic surveillance site (DSS) of the Child Health Research Foundation and the International Centre for Diarrhoeal Disease Research, Bangladesh in Mirzapur, Bangladesh. Mirzapur is a rural subdistrict of Bangladesh located approximately $60 \mathrm{~km}$ north of Dhaka, the capital city. Bangladesh is classified by the World Bank as an LMIC, with a per capita gross domestic product of Int $\$ 4372$ in 2018, ranking 137th among 182 countries. Mirzapur is representative among
Bangladesh subdistricts, falling towards the middle in terms of educational, health and economic indicators. The economy is mostly dependent on agriculture. Mirzapur is also broadly representative of the Gangetic plains region of the Indian subcontinent. There are three main seasons in Mirzapur: summer (March-June), monsoon (June-October) and winter (October-March). The Mirzapur DSS was created in 2007 and has nearly 300000 individuals enrolled in approximately 70000 households. The DSS is served by Kumudini Hospital, a private, non-profit 750-bed referral hospital.

\section{Study design}

We conducted a community-based cross-sectional survey of households enrolled in the Mirzapur DSS from November 2017 to April 2018. This study was nested within the weekly household visits that community health workers (CHW) perform while conducting active surveillance of serious childhood illness within the Mirzapur DSS. The target sample size of 2149 under-5 children was calculated assuming a $6.5 \%$ prevalence of atopic dermatitis and a $95 \%$ CI of $\pm 1 \%$ precision in a population of 27000. Each of the 156 villages in the DSS was subdivided into 110 clusters and ten clusters among them were chosen at random to be included in the study, achieving the desired population-based sample. The CHWs were bilingual, had an educational attainment of secondary school or higher, and were well known to the community. They attended 2 days of classroom instruction on the aims of the study and on atopic disease identification, ISAAC protocol, UK Working Party Criteria, and the research study protocol after which they performed 1 day of field practice with observation and feedback. One month after the initial training session, they received a refresher training. Supervisors, who also attended the training, monitored the CHWs' work weekly.

\section{Surveillance for atopic diseases}

CHWs visited DSS members in their homes to administer oral informed consent for enrolment. As this study was nested within a severe childhood illness surveillance programme, the female head of household typically responded for herself and for all of the children, including adolescents. Other adults within the household responded to questionnaires about their own health. Questionnaires took between 5 and $20 \mathrm{~min}$ per person to complete; more questions were asked if the participant screened positive for any one condition. Households with all adults missing during the first visit were visited a second time and if missing on the second visit, that household was excluded from the study.

\section{International Study of Asthma and Allergies in Childhood}

The questionnaire was translated from English to Bangla (by author MJU) and back-translated from Bangla to English to verify accuracy by Zabed bin Ahmed, Senior Research Officer at the Child Health Research Foundation. The questionnaire was pilot tested in the community, 
discussed with CHWs and adjusted following the recommendations of the ISAAC phase 3 Manual. ${ }^{18}$ Demographic data were obtained from the Mirzapur DSS data repository linked to the individual and household identification numbers of participants in this study.

The 12-month prevalence of atopic dermatitis, asthma and rhinitis were ascertained using the ISAAC Phase 3 core symptom questionnaires. Atopic dermatitis was defined as an itchy rash at any time coming and going for at least 6 months that had at any time affected the folds of the elbows, behind the knees, in front of the ankles, under the buttocks or around the neck, ears or eyes in the past 12 months. Severe atopic dermatitis was defined as being kept awake one or more nights per week on average by this itchy rash in the past 12 months. While previous surveys with ISSAC have not included infants, if the child was under the age of 6 months we considered any presence of rash as affirmative and determined a positive screen by an affirmative response to the question regarding anatomical location of the rash as described above. Asthma was defined as the presence of whistling or wheezing in the previous 12 months. Severe asthma was defined as any of the following in the previous 12 months: more than three attacks of wheezing, sleep disturbed by wheezing on average one or more nights per week, or at least one episode where wheezing limited speech to only two words or cries at a time between breaths. Rhinitis was defined as sneezing, rhinorrhoea or nasal obstruction in the previous 12 months not associated with the cold or influenza. Severe rhinitis was defined as having this nose problem interfere with daily activities 'a lot' in the previous 12 months.

\section{UK criteria}

We also administered the UK criteria, ${ }^{19-21}$ a modification of the Hanifin and Rajka criteria, ${ }^{22}$ to screen for atopic dermatitis since the ISAAC questionnaires have been primarily used in children over the age of 5 years. The ISAAC and UK criteria have been administered together in previous studies among non-Caucasian populations and have yielded heterogeneous results. ${ }^{23-25}$ However, the UK criteria have been validated in infants ${ }^{25} 26$ and young children. ${ }^{21}$ The 'questions-only' format was used as recommended for population-based surveys. ${ }^{27-29}$ Using this criteria, atopic dermatitis was defined as having a history of itchy skin within the past 12 months and at least two of the following: (1) history of flexural dermatitis (fronts of elbows, behind the knees, fronts of ankles, around the neck, on the cheeks or around the eyes), (2) onset <age of 2 years (not applied if a child was $<4$ years of age), (3) personal history of asthma or allergic rhinitis or maternal/paternal history of either if a child was $<4$ years of age and (4) affected by dry skin in general.

\section{Data analysis}

Study data were collected and managed using Research Electronic Data Capture tools hosted at the Stanford University School of Medicine. ${ }^{30}$
For each of the four conditions (ISAAC atopic dermatitis, asthma and rhinitis and UK criteria atopic dermatitis), we calculated the prevalence using the total number of individuals in each age group as the denominator for that age group. In one instance where age was missing, that individual was deleted from analysis. The corresponding 95\% CIs were calculated separately for each age group. In order to have a sufficient sample size for comparison of atopic conditions between groups while still maintaining age groups at various developmental stages, we ran $\chi^{2}$ tests on the following age groups: under 5 years, $6-14$ years, $15-24$ years and $\geq 25$ years. We used bivariate logistic regression analysis to calculate ORs. Asset-based wealth index quintiles were calculated based on source of drinking water, toilet facility, household building materials, livestock, land use and number of rooms in the home. ${ }^{31}$ Wealth indices were calculated using the entire Mirzapur DSS, of which our sample is a subset as previously described. We used SAS Studio 3.8 (SAS Institute) to perform all data analysis.

\section{Patient and public involvement}

Patients or the public were not involved in the design, conduct, reporting, or dissemination plans of our research.

Verbal informed consent was obtained from heads of households after informing them of the study's procedures and the purpose of the study.

\section{RESULTS}

During the study period, 2068 households were approached for enrolment; no households that were approached refused participation. We surveyed 7275 individuals with a mean age of 18.8 years (SD 14.4 years) of whom $2242(30.8 \%)$ were under 5 years of age (table 1$)$. The sample included $3425(47.1 \%)$ men and 3850 $(52.9 \%)$ women. The majority of households $(86.6 \%)$ were Muslim. Approximately half of adult women (50.7\%) and men $(48.9 \%$, not shown) had not completed primary school. The highest wealth index quintile comprised $32.9 \%$ of the sample and the lowest comprised $5.6 \%$.

\section{Atopic dermatitis}

The UK criteria identified 550 participants as having atopic dermatitis for an overall 12-month prevalence of $7.6 \%$ (95\% CI $7.0 \%$ to $8.1 \%$ ). Atopic dermatitis prevalence showed a bimodal pattern increasing from $9.3 \%$ in children $<1$ year $(95 \%$ CI $6.7 \%$ to $12.0 \%)$ and peaking at $18.8 \%$ (95\% CI $15.2 \%$ to $22.4 \%$ ) at 2 years (figure 1 ). Prevalence then decreased to $3.8 \%$ (95\% CI $2.1 \%$ to $5.4 \%$ ) in children 6-9 years old and increased again during adolescence to $6.4 \%$ (95\% CI $3.9 \%$ to $9.0 \%$ ) in the 15-19 years age group. In adulthood, the prevalence decreased to a low of $2.8 \%$ (95\% CI $1.4 \%$ to $4.3 \%$ ) in the $\geq 40$ years age group. Females $\geq 25$ years had a higher prevalence of atopic dermatitis than males $(5.9 \%$ vs $3.0 \%$, 
Table 1 Demographic characteristics of the study sample $(\mathrm{N}=7275)$

\begin{tabular}{|c|c|}
\hline & $\%(n)^{*}$ \\
\hline Age in years, mean (SD) & $18.8(14.4)$ \\
\hline$<1$ year & $6.2(450)$ \\
\hline 1 year & $6.5(473)$ \\
\hline 2 years & $6.3(458)$ \\
\hline 3 years & $6.1(446)$ \\
\hline 4 years & $5.7(415)$ \\
\hline 5 years & $1.5(106)$ \\
\hline $6-9$ years & $6.9(504)$ \\
\hline $10-14$ years & $6.0(435)$ \\
\hline $15-19$ years & $4.9(357)$ \\
\hline 20-24 years & $9.5(690)$ \\
\hline 25-29years & $13.6(992)$ \\
\hline 30-34 years & $11.9(866)$ \\
\hline 35-39years & $8.1(586)$ \\
\hline$\geq 40$ years & $6.8(497)$ \\
\hline \multicolumn{2}{|l|}{ Sex } \\
\hline Male & $47.1(3424)$ \\
\hline Female & $52.9(3851)$ \\
\hline \multicolumn{2}{|l|}{ Religion } \\
\hline Muslim & $86.6(6291)$ \\
\hline Hindu & $13.3(963)$ \\
\hline \multicolumn{2}{|c|}{ Highest female education ( $N=2053)$} \\
\hline No primary & $9.9(205)$ \\
\hline Less than primary & $40.5(837)$ \\
\hline Primary & $25.7(530)$ \\
\hline Some secondary & $10.4(210)$ \\
\hline Secondary or higher & $13.2(271)$ \\
\hline \multicolumn{2}{|l|}{ Wealth quintile } \\
\hline Poor & $5.6(111)$ \\
\hline Lower middle & $14.6(288)$ \\
\hline Middle & $22.0(432)$ \\
\hline Upper middle & $24.9(490)$ \\
\hline Wealthy & 32.9 (647) \\
\hline
\end{tabular}

*Percentages may not sum to $100 \%$ due to rounding

$\mathrm{p}=0.001$ ); there was no difference in childhood prevalence between the sexes.

ISAAC identified 498 participants with atopic dermatitis for an overall 12-month prevalence of $8.1 \%$ (95\% CI $4.6 \%$ to $11.6 \%$ ) ranging from a high of $14.9 \%$ (95\% CI $11.6 \%$ to $18.1 \%$ ) at 2 years to lows of $3.2 \%$ (95\% CI $1.8 \%$ to $4.7 \%$ ) and $3.4 \%$ (95\% CI $1.8 \%$ to $5.0 \%$ ) in the $35-39$ years and $\geq 40$ year age groups, respectively (figure 1 ). Similar to the UK criteria, the ISAAC results displayed a bimodal trend with peak prevalence in early childhood and in adolescence $(9.0 \%$ (95\% CI $6.0 \%$ to $11.9 \%)$ in the

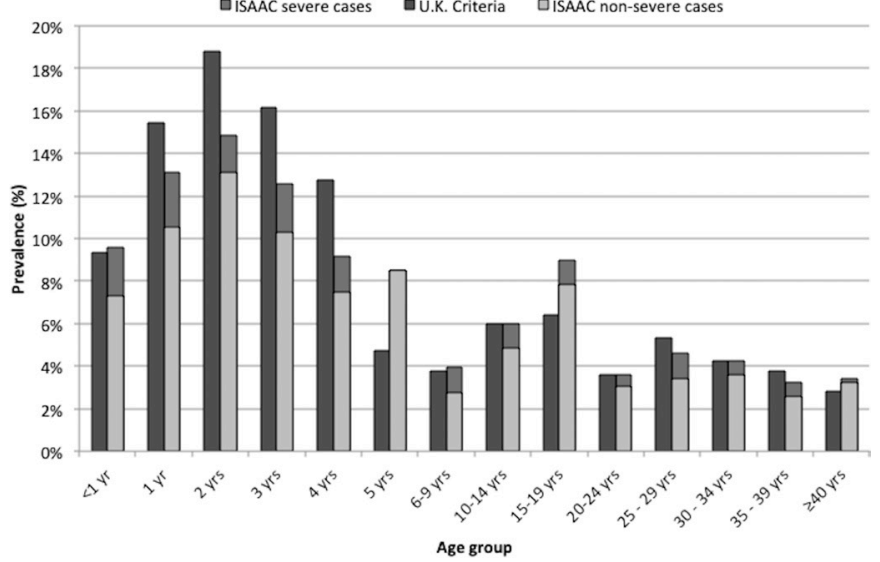

Figure 1 The 12-month prevalence of atopic dermatitis and proportion of severe cases by age group of subjects in Mirzapur, Bangladesh. ISAAC, International Study of Asthma and Allergies in Childhood.

15-19years age group). Prevalence of atopic dermatitis was also higher in females than males in adulthood $(5.3 \%$ vs $3.1 \%, \mathrm{p}=0.003$ ) by this measure. Severe disease was found among $12.4 \%$ of those affected overall. Males also had more severe disease in early adulthood than females (33.3\% vs $4.4 \%, \mathrm{p}=0.015)$. There were no differences in severity among the other age groups.

\section{Asthma}

Five hundred and eight participants met the ISAAC criteria for asthma for an overall 12-month prevalence of $7.0 \%$ (95\% CI $6.4 \%$ to $7.6 \%$ ). The highest prevalence was $20.1 \%$ (95\% CI $16.4 \%$ to $23.8 \%$ ) in children 2 years old (figure 2). The prevalence then down-trended and reached its nadir at $2.2 \%$ in the $15-19$ (95\% CI $0.7 \%$ to $3.8 \%$ ) and $20-24$ (95\% CI $1.1 \%$ to $3.3 \%)$ years age groups before increasing again slightly to $3.9 \%$ (95\% CI $2.7 \%$ to $5.1 \%$ ) and $4.1 \%$ (95\% CI $2.5 \%$ to $5.7 \%$ ) in the 25-29 years and 35-39 age groups, respectively. The prevalence of asthma was higher in males under 5 years of age compared with females $(16.2 \%$ vs $13.3 \%$,

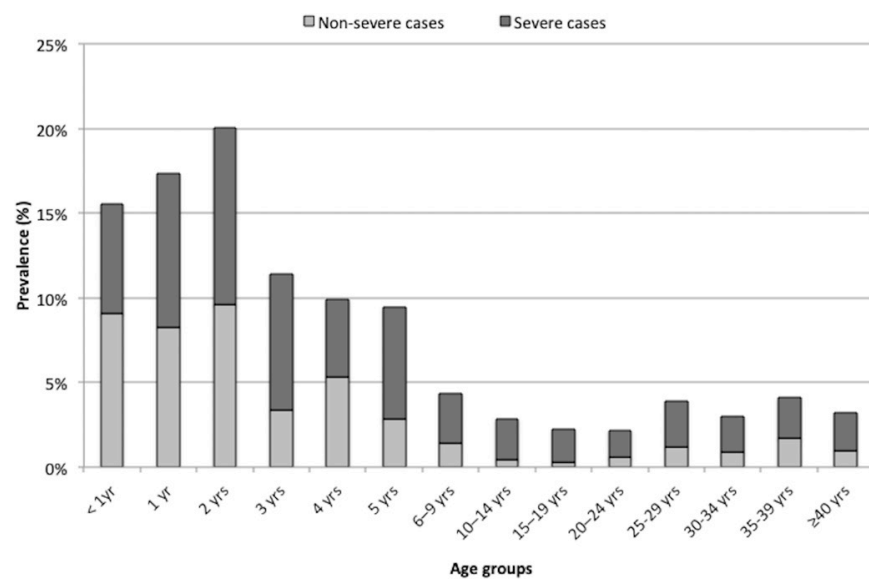

Figure 2 The 12-month prevalence of asthma and proportion of severe cases by age group of subjects in Mirzapur, Bangladesh. 


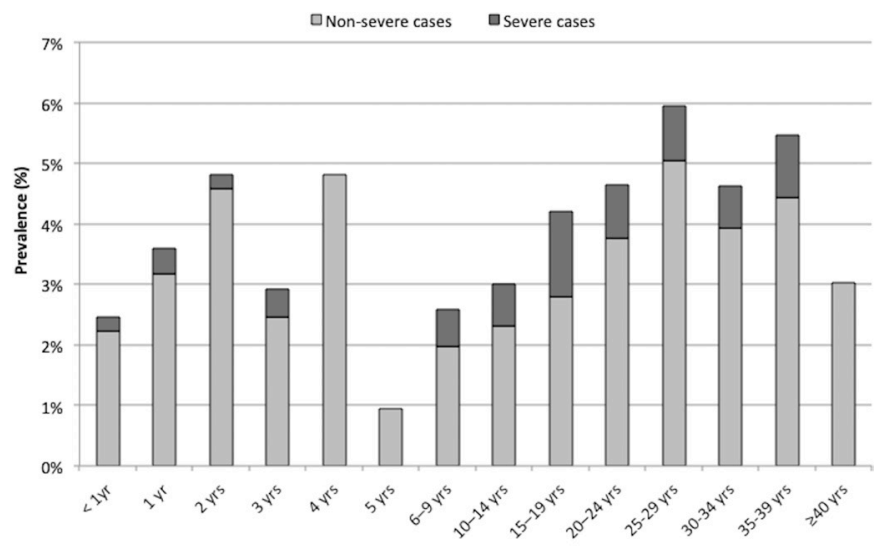

Age groups

Figure 3 The 12-month prevalence of rhinitis and proportion of severe cases by age group of subjects in Mirzapur, Bangladesh.

$\mathrm{p}=0.049)$. Overall, $65.6 \%$ of those identified with asthma met criteria for severe disease. Those $>5$ years were more likely to have severe disease than those $\leq 5$ years $(73.2 \%$ vs $61.2 \%, \mathrm{p}=0.010)$. There was no difference in prevalence of severe asthma between the sexes $(66.7 \%$ male vs $64.4 \%$ female, $\mathrm{p}=0.620$ ).

\section{Rhinitis}

For rhinitis, 303 participants met ISAAC criteria for an overall 12-month prevalence of $4.2 \%$ (95\% CI $3.7 \%$ to $4.6 \%)$. Prevalence was highest among participants from the highest wealth quintile $(5.1 \%, \mathrm{p}=0.003)$. Among under-5 children, the prevalence was highest in the 2-year age group $(4.8 \%, 95 \%$ CI $2.9 \%$ to $6.8 \%)$ and 4-year age groups $(4.8 \%, 95 \%$ CI $2.8 \%$ to $6.9 \%$ ) (figure 3 ). Starting from a low of $0.9 \%(95 \%$ CI $0.0 \%$ to $2.8 \%)$ at 5 years, prevalence increased until the 25-29 years age group where it peaked at $6.0 \%$ (95\% CI $4.5 \%$ to $7.4 \%$ ) and decreased again to $3.0 \%$ (95\% CI $1.5 \%$ to $4.5 \%$ ) in the $\geq 40$ years age group. Males had a higher prevalence in early childhood ( $4.3 \%$ vs $2.7 \%, \mathrm{p}=0.017)$ and lower prevalence in adulthood $(3.7 \%$ vs $6.5 \%, \mathrm{p}<0.001)$ compared with females in the same age groups. Overall, $14.5 \%$ of those identified with rhinitis had severe disease and those $>5$ years had a higher proportion of severe rhinitis than those $\leq 5$ years $(17.3 \%$ vs $7.2 \%, \mathrm{p}=0.027)$.

\section{Physician diagnosis}

The proportion of participants who had received a doctor's diagnosis was 25/549 $(4.6 \%)$ for the UK criteria, 20/495 (4.0\%) for ISAAC atopic dermatitis, 95/507 (18.7\%) for asthma and $82 / 300(27.3 \%)$ for rhinitis. Those with severe disease were significantly more likely to have received a doctor's diagnosis compared with those without severe disease for atopic dermatitis $(30.0 \%$ vs $11.7 \%, \mathrm{p}=0.015)$, asthma $(85.0 \%$ vs $60.4 \%, \mathrm{p}<0.001)$ and rhinitis $(34.2 \%$ vs $7.3 \%, \mathrm{p}<0.001)$. For asthma, the proportion of participants who had received a physician's diagnosis increased from $7.5 \%$ for the lowest wealth quintile to $29.7 \%(\mathrm{p}<0.001)$ for the highest quintile. A similar

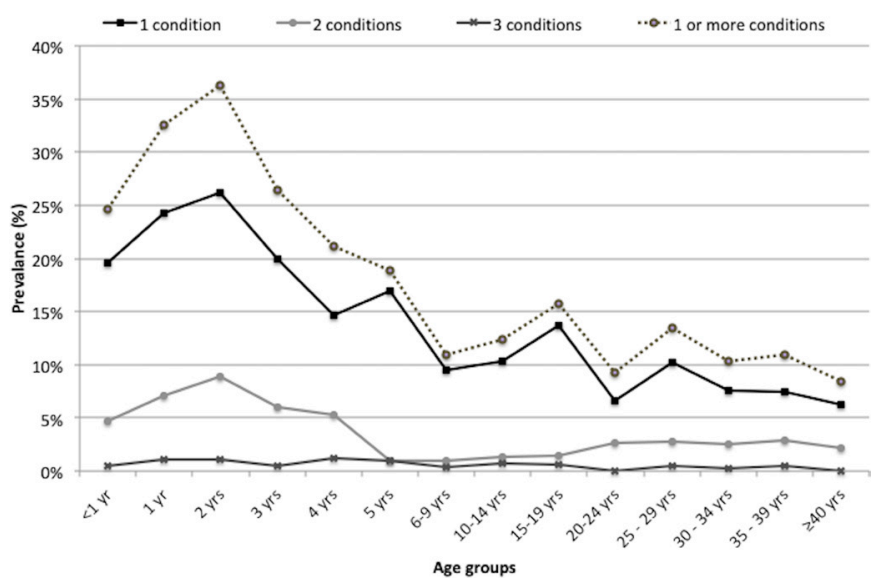

Figure 4 Proportions of comorbid atopic conditions by age group of subjects in Mirzapur, Bangladesh.

trend was found with rhinitis ranging from $12.5 \%$ in the lowest wealth quintile to $39.8 \%(\mathrm{p}=0.003)$ in the highest quintile. No association was found between atopic dermatitis diagnosis and wealth quintile.

\section{Concurrent atopic disease}

The prevalence of having any one atopic condition peaked early in life, affecting over one-third (36.2\%) of children 2 years of age (figure 4). The prevalence of having two atopic conditions also peaked at 2 years of age $(10 \%)$, was lowest $(1.4 \%)$ in children $6-9$ years old and rose again slightly in adulthood to between $3.3 \%$ and $3.4 \%$ in the 25-29 and 35-39 age groups, respectively. The percentage of those with all three conditions ranged from $0.0 \%$ to $1.2 \%$. Participants with atopic dermatitis as defined by the UK criteria had a higher prevalence of asthma (24.2\% vs $5.6 \%$, p $<0.001$; OR 5.41 (95\% 4.34$6.75)$ ) and rhinitis (15.6\% vs $3.2 \%, \mathrm{p}<0.001$; OR 4.49 (95\% CI 3.55 to 5.68)) compared with those without atopic dermatitis. The same pattern was found for those with atopic dermatitis as defined by the ISAAC criteria for asthma $(21.9 \%$ vs $5.9 \%, \mathrm{p}<0.001$; OR $5.56(95 \%$ CI 4.26 to 7.26$)$ ) and rhinitis ( $12.1 \%$ vs $3.6 \%, \mathrm{p}<0.001$; OR 3.68 (95\% CI 2.73 to 4.96$)$ ). Similarly, those with asthma had a higher prevalence of rhinitis compared with those without asthma (20.3\% vs $2.9 \%$, p<0.001; OR $8.39(95 \%$ CI 6.48 to 10.86 )).

\section{DISCUSSION}

To our knowledge, this is the first description of the period prevalence of atopic conditions over the life course from infancy through adulthood reported from the Indian subcontinent. Atopic dermatitis and asthma followed a similar pattern, peaking in the second year of life and decreasing in prevalence with age, although with an upturn in prevalence of atopic dermatitis during adolescence. Longitudinal studies from HICs similarly have documented that children aged 2 years and under 3 years have the highest prevalences of atopic dermatitis and wheezing, respectively. ${ }^{32-34}$ In contrast, rhinitis was 
relatively stable until increasing from adolescence to adulthood. Global estimates of rhinitis are heterogeneous and difficult to compare. ${ }^{35}$

As found in multiple previous studies, ${ }^{12}{ }^{36-38}$ having atopic dermatitis was associated with increased odds of concurrently having asthma or rhinitis, and asthma was associated with rhinitis. Thus, comorbid development of these atopic diseases clearly occurs in this population. However, the proportion of those affected with any one condition decreased with age and those with two or more conditions did not substantially increase. Research among a Ugandan birth cohort found that atopic sensitisation increased to the level of HICs with age, but the prevalence of atopic disease did not increase as expected based on data from HICs leading the authors to conclude that the atopic march did not occur in this population. ${ }^{12}$ While our data support the comorbid nature of these conditions, we lack the longitudinal data that would allow us to suggest a driving mechanism, such as the atopic march.

The most recent estimate of atopic dermatitis in Bangladesh was reported in 2005 among 6-7 and 13-14years age groups to be $6.0 \%$ and $7.1 \%$, respectively, and $6.5 \%$ overall. ${ }^{39}$ This falls within both the UK criteria and ISAAC measures for our 10-14 years age group but is higher than our estimates for the 6-9years age group. The overall estimate is also within our sample's estimated prevalence when the two groups are combined. More recently asthma prevalence has been reported as high as $20.2 \%$ and $6.8 \%$ in 4.5 and 10 years old, respectively. ${ }^{40}$ These are higher than the estimates reported here; however, an asthma prevalence of $8.7 \%$ in 5 years from the same surveillance site was also reported, similar to the prevalence we report here. ${ }^{41}$ These differences in prevalence could be due to environmental variation between the research sites within the country. Wide variations were seen between Indian centres from the ISAAC Phase 3 study which reported prevalence ranging from $4.6 \%$ to $45.7 \%$ for rhinitis and $0.9 \%$ to $9.2 \%$ for eczema among $13-14$ years. ${ }^{42}$ While we followed the ISAAC Phase 3 Manual instructions for translation closely, there is also the possibility that differences in translation resulted in different understandings of the questions for our study sample compared with other samples within the country or region.

The prevalence provided by the UK criteria was higher than the ISAAC prevalence for $1-5$ years. The ISAAC questionnaires are typically deployed in populations $6-7$ and 13-14 years old but they have been used in children as young as 2 years in modified versions. ${ }^{12}$ Here, we used a modified ISAAC questionnaire for atopic dermatitis and it showed good agreement with the UK criteria in children $<1$ year. The deviation in the $1-4$ years age groups, with higher prevalence measured by the UK criteria than ISAAC, was likely due to the use of the 'questions only' format of the UK criteria, which uses one major criterion plus two or more minor criteria and eliminates the photographical protocol. This format showed increased sensitivity and decreased specificity in a paediatric population under 11 years of age. ${ }^{28}$ The original authors of the UK critieria also suggested that in communities with lower prevalence of atopic dermatitis, this modified version may exhibit a reduced specificity due to increased prevalence of pruritus of other aetiologies. ${ }^{28}$

Of concern, there was a paucity of official medical diagnoses among participants who were positive by the study's various criteria. There are several potential reasons for this, including limited care-seeking, and limitations in reaching a medical diagnosis. Rhinitis was most likely to be diagnosed, possibly due to it being a condition experienced later in life and frequently for more years than asthma and atopic dermatitis. Asthma was more commonly medically diagnosed than atopic dermatitis, likely due in part to a higher proportion of severe disease. Rasul et al found that within Bangladesh, higher educational attainment and socioeconomic status, shorter distance from the household to the health centre, and fewer household members with a chronic disease were associated with seeking care for a chronic non-communicable disease, such as asthma, from a qualified provider. ${ }^{43}$ They also found a high burden of out-of-pocket medical expenditures, mostly related to pharmaceutical treatments. This supports our findings that those from the highest wealth quintiles were more likely to have received a diagnosis of their condition. We also speculate that there may be limitations in the capabilities of medical practitioner to identify atopic diseases and distinguish them from other common conditions, for example, differentiating scabies from atopic dermatitis. Taken together, it is clear that there is an important opportunity to increase affordable medical interventions, both in identification and diagnosis of cases as well as in prevention and treatment.

\section{Limitations}

Cross-sectional studies have well-known limitations inherent to their design. Recording the disease prevalence across age groups is not as informative as recording the natural history of a disease especially in such a rapidly LMIC such as Bangladesh where the living conditions and health systems experienced by age groups through their respective lifetimes are substantially different. While cross-sectional data do provide insight into the burden of disease of various age groups, a prospective cohort study would more easily allow us to draw conclusions about risk factors and the relationships among the three atopic diseases. There is a lack, however, of longitudinal data from LMICs on prevalence of atopic diseases. Additionally, while households were chosen at random from a subset of zones within the DSS, there was an imbalance of wealth quintiles among all participants, suggesting that there was some imbalance in the study subset. We are missing asset data from 50 households-33 migrated out of the DSS area and 17 were not home during the DSS assessment. Poorer households may have been more likely to migrate out of the area for work or more likely to have all adults engaged in the workforce such that they would not be available during DSS activities. 


\section{CONCLUSION}

Research is beginning to suggest differences in the pattern and etiologies of atopic diseases between HICs and LMICs. As LMICs experience increasing prevalence of these conditions, research should continue to re-evaluate the associations among atopic diseases previously established by data from HICs in both paediatric and adult populations. Additionally, given the high disease burden in early childhood and substantial proportion that persists into adulthood, there is great opportunity to increase educational outreach to both healthcare providers and patients and their families about the medical importance of these conditions and options for management. Lastly, it is imperative that policies are formulated to allow increased access to affordable medical interventions for diagnosis, treatment and prevention for all age groups.

\section{Twitter Gary L Darmstadt @gdarmsta}

Contributors CP and GLD conceptualised and designed the study, interpreted the data, drafted the initial manuscript and reviewed and revised the manuscript. $\mathrm{CP}$ also designed the data collection instruments, participated in oversight of data collection and conducted the analysis of the data. MJU and SKS participated in designing the study and the data collection instruments, supervised data collection and reviewed and revised the manuscript. All authors approved the final manuscript as submitted and agreed to be accountable for all aspects of the work.

Funding CP received a Medical Scholars award from the Stanford University School of Medicine, and a Benjamin H Kean Travel Fellowship from the American Society of Tropical Medicine and Hygiene. REDCap platform services are made possible by the Stanford University School of Medicine Research Office. The REDCap platform services at Stanford are subsidised by the National Center for Research Resources and the National Center for Advancing Translational Sciences, National Institutes of Health (NIH).

Disclaimer The data content is solely the responsibility of the authors and does not necessarily represent the official views of the $\mathrm{NIH}$.

Competing interests None declared.

Patient and public involvement Patients and/or the public were not involved in the design, or conduct, or reporting, or dissemination plans of this research.

Patient consent for publication Not required.

Ethics approval Ethical approval was obtained from the Institutional Review Boards at both the Stanford University School of Medicine (protocol \#41405) and the Bangladesh Institute of Child Health in Dhaka.

Provenance and peer review Not commissioned; externally peer reviewed.

Data availability statement Data are available on reasonable request to the senior author through a data sharing agreement.

Open access This is an open access article distributed in accordance with the Creative Commons Attribution Non Commercial (CC BY-NC 4.0) license, which permits others to distribute, remix, adapt, build upon this work non-commercially, and license their derivative works on different terms, provided the original work is properly cited, appropriate credit is given, any changes made indicated, and the use is non-commercial. See: http://creativecommons.org/licenses/by-nc/4.0/.

ORCID iD

Gary L Darmstadt http://orcid.org/0000-0002-7522-5824

\section{REFERENCES}

1 Bantz SK, Zhu Z, Zheng T. The atopic March: progression from atopic dermatitis to allergic rhinitis and asthma. J Clin Cell Immunol 2014;5:202.

2 Global Asthma Network. The global asthma report 2019. Auckland, New Zealand, 2018.

3 Hay RJ, Johns NE, Williams HC, et al. The global burden of skin disease in 2010: an analysis of the prevalence and impact of skin conditions. J Invest Dermatol 2014;134:1527-34.
4 Odhiambo JA, Williams HC, Clayton TO, et al. Global variations in prevalence of eczema symptoms in children from Isaac phase three. J Allergy Clin Immunol 2009;124:e23:1251-8.

5 Asher MI, Montefort S, Björkstén B, et al. Worldwide time trends in the prevalence of symptoms of asthma, allergic rhinoconjunctivitis, and eczema in childhood: Isaac phases one and three repeat multicountry cross-sectional surveys. Lancet 2006;368:733-43.

6 Aït-Khaled N, Pearce N, Anderson HR, et al. Global map of the prevalence of symptoms of rhinoconjunctivitis in children: the International study of asthma and allergies in childhood (Isaac) phase three. Allergy 2009;64:123-48.

7 Williams $\mathrm{H}$, Stewart A, von Mutius $\mathrm{E}$, et al. Is eczema really on the increase worldwide? J Allergy Clin Immunol 2008;121:e15:947-54.

8 Hill DA, Spergel JM. The atopic March: critical evidence and clinical relevance. Ann Allergy Asthma Immunol 2018;120:131-7.

9 Weinmayr G, Weiland SK, Björkstén B, et al. Atopic sensitization and the International variation of asthma symptom prevalence in children. Am J Respir Crit Care Med 2007;176:565-74.

10 Solis Soto MT, Patiño A, Nowak D, et al. Prevalence of asthma, rhinitis and eczema symptoms in rural and urban school-aged children from Oropeza Province - Bolivia: a cross-sectional study. BMC Pulm Med 2014;14:40.

11 Flohr C, Weiland SK, Weinmayr G, et al. The role of atopic sensitization in flexural eczema: findings from the International study of asthma and allergies in childhood phase two. J Allergy Clin Immunol 2008;121:141-7.

12 Lule SA, Mpairwe H, Nampijja M, et al. Life-Course of atopy and allergy-related disease events in tropical sub-Saharan Africa: a birth cohort study. Pediatr Allergy Immunol 2017;28:377-83.

13 Wills-Karp M, Santeliz J, Karp CL. The germless theory of allergic disease: revisiting the hygiene hypothesis. Nat Rev Immunol 2001;1:69-75.

14 Beasley R, Semprini A, Mitchell EA. Risk factors for asthma: is prevention possible? Lancet 2015;386:1075-85.

15 Strachan DP, Aït-Khaled N, Foliaki S, et al. Siblings, asthma, rhinoconjunctivitis and eczema: a worldwide perspective from the International study of asthma and allergies in childhood. Clin Exp Allergy 2015;45:126-36.

16 Flohr C, Quinnell RJ, Britton J. Do helminth parasites protect against atopy and allergic disease? Clin Exp Allergy 2009;39:20-32.

17 Leonardi-Bee J, Pritchard D, Britton J. Asthma and current intestinal parasite infection: systematic review and meta-analysis. Am J Respir Crit Care Med 2006;174:514-23.

18 Ellwood P, Asher MI, Beasley R, et al. ISAAC phase three manual. Auckland, 2000.

19 Williams HC, Burney PG, Hay RJ, et al. The U.K. Working Party's diagnostic criteria for atopic dermatitis. I. derivation of a minimum set of discriminators for atopic dermatitis. Br J Dermatol 1994:131:383-96.

20 Williams HC, Burney PG, Strachan D, et al. The U.K. Working Party's diagnostic criteria for atopic dermatitis. II. Observer variation of clinical diagnosis and signs of atopic dermatitis. Br J Dermatol 1994;131:397-405.

21 Williams HC, Burney PG, Pembroke AC, et al. The U.K. Working Party's diagnostic criteria for atopic dermatitis. III. independent Hospital validation. Br J Dermatol 1994;131:406-16.

22 Hanifin JM, Rajka G. Diagnostic features of atopic dermatitis. Acta Derm Venereol 1980;92:44-7.

23 Chalmers DA, Todd G, Saxe N, et al. Validation of the U.K. Working Party diagnostic criteria for atopic eczema in a Xhosa-speaking African population. Br J Dermatol 2007;156:111-6.

24 Haileamlak A, Lewis SA, Britton J, et al. Validation of the International study of asthma and allergies in children (Isaac) and U.K. criteria for atopic eczema in Ethiopian children. Br J Dermatol 2005;152:735-41.

25 De D, Kanwar AJ, Handa S. Comparative efficacy of Hanifin and Rajka's criteria and the UK Working Party's diagnostic criteria in diagnosis of atopic dermatitis in a hospital setting in North India. $J$ Eur Acad Dermatol Venereol 2006;20:853-9.

26 Fleming S, Bodner C, Devereux G, et al. An application of the United Kingdom Working Party diagnostic criteria for atopic dermatitis in Scottish infants. J Invest Dermatol 2001;117:1526-30.

27 Popescu CM, Popescu R, Williams H, et al. Community validation of the United Kingdom diagnostic criteria for atopic dermatitis in Romanian schoolchildren. Br J Dermatol 1998;138:436-42.

28 Williams HC, Burney PG, Pembroke AC, et al. Validation of the U.K. diagnostic criteria for atopic dermatitis in a population setting. U.K. diagnostic criteria for atopic dermatitis Working Party. Br J Dermatol 1996;135:12-17.

29 Williams HC. So how do I define atopic eczema? A pratical training manual for research wishing to define atopic eczema. UK: University of Nottingham, 1996. 
30 Harris PA, Taylor R, Thielke R, et al. Research electronic data capture (REDCap)--a metadata-driven methodology and workflow process for providing translational research informatics support. J Biomed Inform 2009;42:377-81.

31 Saif-Ur-Rahman KM, Anwar I, Hasan M, et al. Use of indices to measure socio-economic status (Ses) in South-Asian urban health studies: a scoping review. Syst Rev 2018;7:196.

32 Illi S, von Mutius E, Lau S, et al. The natural course of atopic dermatitis from birth to age 7 years and the association with asthma. $J$ Allergy Clin Immunol 2004;113:925-31.

33 Halkjaer LB, Loland L, Buchvald FF, et al. Development of atopic dermatitis during the first 3 years of life: the Copenhagen prospective study on asthma in childhood cohort study in high-risk children. Arch Dermatol 2006;142:561-6.

34 Resiliac J, Grayson MH. Epidemiology of infections and development of asthma. Immunol Allergy Clin North Am 2019;39:297-307.

35 Mims JW. Epidemiology of allergic rhinitis. Int Forum Allergy Rhinol 2014;4 Suppl 2:S18-20.

36 Pinart M, Benet M, Annesi-Maesano I, et al. Comorbidity of eczema, rhinitis, and asthma in IgE-sensitised and non-lgE-sensitised children in MeDALL: a population-based cohort study. Lancet Respir Med 2014;2:131-40.
37 Ballardini N, Kull I, Lind T, et al. Development and comorbidity of eczema, asthma and rhinitis to age 12: data from the BAMSE birth cohort. Allergy 2012;67:537-44.

38 Khan DA. Allergic rhinitis and asthma: epidemiology and common pathophysiology. Allergy Asthma Proc 2014;35:357-61.

39 Kabir ML, Rahman F, Hassan MQ, et al. Asthma, atopic eczema and allergic rhino-conjunctivitis in school children. Mymensingh Med J 2005;14:41-5.

40 Nozawa Y, Hawlader MDH, Ferdous F, et al. Effects of intrauterine growth restriction and postnatal nutrition on pediatric asthma in Bangladesh. J Dev Orig Health Dis 2019;10:627-35.

41 Takeuchi H, Khan AF, Hasan MI, et al. Comment on IgE responses to Ascaris and mite tropomyosins are risk factors for asthma. Clin Exp Allergy 2016;46:178-80.

42 Singh S, Sharma BB, Salvi S, et al. Allergic rhinitis, rhinoconjunctivitis, and eczema: prevalence and associated factors in children. Clin Respir J 2018;12:547-56.

43 Rasul FB, Kalmus O, Sarker M, et al. Determinants of health seeking behavior for chronic non-communicable diseases and related out-ofpocket expenditure: results from a cross-sectional survey in northern Bangladesh. J Health Popul Nutr 2019;38:48. 